\title{
Reopening the Convergence Debate: A New Look at Cross-Country Growth Empirics
}

\author{
Francesco Caselli, Gerardo Esquivel and Fernando Lefort ${ }^{1}$ \\ Journal of Economic Growth, 1996.
}

\footnotetext{
${ }^{1}$ Harvard University. We wish to thank Alberto Alesina, Robert Barro, John Campbell, John Driscoll, Guido Imbens, Aart Kraay, David Laibson, John Leahy, Jong-Wha Lee, Jordan Rappaport, Jose Tavares, Jaume Ventura and seminar partecipants at Harvard University and at the Seventh World Congress of the Econometric Society for useful remarks. Special thanks are due to Gary Chamberlain, Dale Jorgenson and Greg Mankiw for illuminating conversations. The comments of an anonymous referee have led to a substantial improvement of the paper, and are also gratefully acknowledged. We are responsible for all errors. Comments are welcome. Please write to any of the authors at: Department of Economics, Littauer Center, Harvard University, Cambridge, MA, 02138 (e-mail: gesquiv@fas.harvard.edu).
} 


\begin{abstract}
There are two sources of inconsistency in existing cross-country empirical work on growth: correlated individual effects and endogenous explanatory variables. We estimate a variety of cross- country growth regressions using a generalized method of moments estimator that eliminates both problems. In one application, we find that per capita incomes converge to their steadystate levels at a rate of approximately $10 \%$ per year. This result stands in sharp contrast to the current consensus, which places the convergence rate at $2 \%$. We discuss the theoretical implications of this finding. In another application, we perform a test of the Solow model. Again, contrary to prior results, we reject both the standard and the augmented version of the model.
\end{abstract}




\section{Introduction}

Almost ten years have elapsed since William Baumol (1986) started the empirical debate on economic convergence. Since then, dozens of researchers have taken up his lead on this and related topics, generating a vast literature of cross-country and cross- regional studies of economic growth and its determinants. Instrumental in this development has been the appearance of Maddison's (1992) and Summers and Heston's (1988, 1991, 1993) data sets of world-wide aggregate series.

In fact, so vast has been the collective research effort on empirical growth, and so intense the exploitation of the Summers and Heston data, that there is a widespread feeling among macroeconomists that the industry has entered the stage of maturity. ${ }^{1}$ In particular, few scholars believe that the Summers and Heston data still harbor new answers to unsettled questions on economic growth. On the contrary, on the specific issue of convergence, the literature seems to have reached a broad consensus (a rare occurrence in empirical macro).

Specifically, in a series of contributions that have shaped the research agenda in growth empirics, Robert Barro (1991), together with Xavier Salai-Martin (1991, 1992, 1995) and Jong-Wha Lee (1994a, 1994b) has argued that countries converge to their steady-state level of per-capita income at a slow rate of approximately 2 or $3 \%$ per year. In other words, the current conventional wisdom is that each year an economy's GDP covers slightly more than $2 \%$ of its distance from the steady state. ${ }^{2}$

This paper challenges the status quo, arguing that the existing empirical literature on cross-country growth relies on inconsistent estimation procedures. Consequently, the convergence rate and the other growth coefficients as obtained in existing contributions are unreliable. Instead, we use the Summers and Heston (1991) and Barro and Lee (1994c) data to offer an alternative, consistent estimate of the rate of convergence which is approximately $10 \%$.

There are two sources of inconsistency in existing cross-country empirical work on growth, and almost all the studies of which we are aware are plagued by at least one of these (the overwhelming majority by both). First, the incorrect treatment of country-specific effects representing differences in technology or tastes gives rise to omitted variable bias. In particular, it is almost always assumed that such effects are uncorrelated with the other

\footnotetext{
1 "Not another growth regression!" has been more than one seminar participant's cry.

${ }^{2}$ See Sala-i-Martin (1994) for a survey emphasizing the "definitive" nature of the $2 \%$ result.
} 
right-hand-side variables. We show that this assumption is necessarily violated due to the dynamic nature of a growth regression.

Second, there exists a strong theoretical argument that at least a subset of the explanatory variables should be expected to be endogenous. Although this problem is generally recognized in the literature, few attempts to control for it have been made. However, our regression and test results indicate a strong role of endogeneity in driving standard results in growth empirics.

We propose to solve these problems by using a panel data, general method of moments estimator. The basic idea is the following. First, we rewrite the growth regression as a dynamic model in the level of per capita GDP. Second, we take differences in order to eliminate the individual effect. Third, we instrument the right-hand-side variables using all their lagged values. The last step eliminates the inconsistency arising from the endogeneity of the explanatory variables, while the differencing removes the omitted variable bias. This estimation procedure is adapted from those described in Holtz-Eakin, Newey and Rosen (1988) and Arellano and Bond (1991).

We use this estimator to revisit two prominent lines of research in growth empirics. First, we reconsider the empirical case for the Solow (1956) model. We use as a bench mark the results in Mankiw, Romer and Weil (1992), which are obtained by a method (ordinary least squares in a crosssection regression) that exposes them to both omitted variable and endogeneity bias. We find that eliminating these biases leads to striking changes in results. For example, Mankiw, Romer and Weil get an estimate of the capital share in output of 0.75 . Since this is too high relative to the national-account figure of about $1 / 3$, they reject the model in favor of an augmented version that includes human capital in the production function. Instead, with our procedure we find a value of 0.10 for the capital share in the basic model. Thus, we also reject, but for the opposite reason, namely, that the capital share is too low. This obviously implies that we reject the augmented version as well. By comparing our results to those in Knight, Loayza and Villanueva (1993), Loayza (1994) and Islam (1995) - which, we argue, feature a correct treatment of the correlated individual effect, but are still affected by endogeneity bias - we also find that both sources of inconsistency have a large impact on standard regression results.

Our second application is in the tradition of the "determinants of growth" equations. The approach consists in regressing the growth rate of output on a broad set of explanatory variables (including the initial level of GDP). Although growth theory is used as a guide for the choice of possible regressors, the specification is quite general, and cannot be interpreted as the reduced form of a single model. 
We take as our starting point the Barro and Lee (1994a) specification, which can be considered the current bench mark in this line of research. ${ }^{3}$ Relative to this bench mark, the new estimator involves dramatic changes in the magnitude and sign of several coefficients. The most striking result concerns the implied estimate of the convergence coefficient. As mentioned at the outset, correcting for endogeneity and omitted variable bias induces a jump in the estimate of convergence from $2-3 \%$ to about $10 \%$ per year. ${ }^{4}$

The main implication of a high rate of conditional convergence is that economies spend most of their time in a neighbourhood of their steady state. As a consequence, we interpret the large differences in observed levels of per capita GDP as arising from differences in steady-state levels, rather than from differences in the position of countries along similar transitional paths. We also present some evidence that substantial differences in technology may play an important role in generating this dispersion in steady-state levels.

The finding of an extremely high rate of convergence is generally at odds with theories of growth that do not feature a steady-state level of output. However, this still leaves a variety of neoclassical growth models that do feature convergence. We argue that, in general, it is difficult to reconcile extremely fast convergence with "augmented" versions of the production function. In other words, our results tend to indicate that the relevant notion of capital is restricted to physical capital only. On the other hand, open economy extensions of the standard neoclassical model generally feature a higher speed of convergence, other things equal, than their closed economy counterparts. These considerations lead us to regard some open economy

\footnotetext{
${ }^{3}$ The specifications in Barro and Lee (1994b) and Barro and Sala-i-Martin (1995, ch. 12) are extremely similar.

${ }^{4} \mathrm{An}$ independent paper by Paul Evans (1995) shares some of the features of ours. In particular, after emphasizing the consistency problems associated with growth regressions, he proposes to take first-differences, and to use lagged output as an instrument. He also finds high convergence. There are, however, important differences. First, he studies a cross-section, rather than a panel of countries. Second, he only instruments with output lagged one period. As a consequence, his estimates are not very precise (he reports a confidence interval for the convergence rate of 3.15 to 100 percent a year). Third, he only estimates an univariate regression of current on lagged output, and retrieves the coefficients on other explanatory variables by an ad hoc procedure that, among other things, requires him to assume that the individual effect is uncorrelated with those variables. The more general GMM procedure we adopt does not require the individual effect to be uncorrelated with any of the right hand side variables. Finally, Evans does not apply the consistent estimator to the whole range of growth regressions that we present. Rather, he confines himself to a single specification, i.e. the augmented Solow model.
} 
version of the (non-augmented) neoclassical growth model with endogenous savings as the most consistent with our empirical results.

The remainder of the paper is organized as follows. Section 2 surveys growth empirics from an econometric point of view, and highlights the sources of inconsistency that plague this literature. Section 3 briefly describes a general method of moments estimator that is consistent for a growth regression. Section 4 applies this method to a test of the Solow model. Section 5 presents an application to a "determinants-of-growth" regression. Section 6 discusses the implications of our results for growth theory. Section 7 concludes and provides some indications for further research.

\section{A Critical Overview of Growth Empirics}

\section{Growth Equations}

The typical cross-country study of economic growth is built on an equation nested in the following general specification:

$$
\ln \left(Y_{i, t}\right)-\ln \left(Y_{i, t-\tau}\right)=\beta \ln \left(Y_{i, t-\tau}\right)+W_{i, t-\tau} \delta+\eta_{i}+\xi_{t}+\epsilon_{i, t}
$$

where $Y_{i, t}$ is per-capita GDP in country $i$ in period $t, W_{i, t}$ is a row vector of determinants of economic growth, $\eta_{i}$ is a country specific effect, $\xi_{t}$ is a period-specific constant, and $\epsilon_{i, t}$ is an error term.

The interpretation of equation (1) depends on the coefficient on lagged GDP. A significantly negative coefficient is consistent with the prediction of the neoclassical growth model, that countries relatively close to their steadystate output level will experience a slowdown in growth (conditional convergence). In this case the variables in $W_{i, t-\tau}$ and the individual effect $\eta_{i}$ are proxies for this long-run level the country is converging to. On the other hand, if $\beta=0$ there is no convergence effect, and the other right-hand-side variables measure differences in steady-state growth rates. Because our estimates below strongly support $\beta<0$, we now focus on the conditionalconvergence interpretation.

The choice of the list of regressors to include in vector $W_{i, t}$ depends on the particular variant of the neoclassical growth model one wishes to examine. Measures of investment in (or stocks of) physical and human capital, indicators of the quality and size of government and indicators of external openness are but some of the many covariates that have been used in determinants-of-growth regressions.

The country-specific effect $\eta_{i}$ captures the existence of other determinants of a country's steady state that are not already controlled for by 
$W_{i, t-\tau}$. The obvious candidates are differences in technology. In the neoclassical model the steady- state level of income depends - among other things - on the parameters of the production function: heterogeneity in these parameters leads to heterogeneity in steady-state output levels. Whether, from a theoretical standpoint, we should expect technology to differ across countries is a hotly debated issue (to which we return below). Empirically, however, it is not legitimate to a priori assume away those differences. As they are unobservable, we treat these differences as individual effects.

A further ingredient of the growth regression is a time-dummy, which may be expected to capture global shocks affecting aggregate production functions across the board.

Equation (1) can be rewritten as:

$$
y_{i, t}=\tilde{\beta} y_{i, t-\tau}+W_{i, t-\tau} \delta+\eta_{i}+\xi_{t}+\epsilon_{i, t}
$$

where $\tilde{\beta}=1+\beta$ and $y_{i, t}=\ln \left(Y_{i, t}\right)$.

Equation (2) makes it clear that estimating (1) is equivalent to estimating a dynamic equation with a lagged-dependent variable on the righthand-side. We now look at how the literature has dealt with this task.

\section{Unsolved Estimation Problems}

\section{Cross-Section Regressions}

The bulk of the vast literature studying growth regressions of the type of (1) is represented by cross-sectional studies of a large sample of developed and developing countries. The dependent variable in these regressions is a time-average of growth rates (e.g., the average growth rate between 1960 and 1985) while on the right-hand-side there usually appear a combination of time-averages of flows (e.g., average investment rate, average rate of government expenditure) and beginning of period stocks (e.g., indexes of educational attainment in 1960; these "stock" variables include beginningof-period per capita GDP). A far from exhaustive list of prominent papers in this vein includes Kormendi and Meguire (1985), Baumol (1986), De Long (1988), Barro (1991), De Long and Summers (1991), Mankiw, Romer and Weil (1992), Barro and Sala-i-Martin (1992), Levine and Renelt (1992) and King and Levine (1993).

The first shortcoming of this literature lies in its treatment of the country-specific effect. It is well known that the standard cross-section estimator (be it ordinary least squares, or any variant that allows for nonspherical disturbances) is only consistent as long as the individual effect can 
be assumed to be uncorrelated with the other right-hand-side variables. However, it is easy to see that such an assumption is necessarily violated in the dynamic framework of a growth regression. To see this, notice that

$$
E\left[\eta_{i} y_{i, t-\tau}\right]=E\left[\eta_{i}\left(\tilde{\beta} y_{i, t-2 \tau}+W_{i, t-2 \tau} \delta+\eta_{i}+\xi_{t-\tau}+\epsilon_{i, t-\tau}\right)\right] \neq 0
$$

where the last inequality follows from the fact that at least $E\left(\eta_{i}^{2}\right) \neq 0$. A consistent treatment of these correlated effects can only be based on data having a time-series dimension.

Because the individual effect proxies for the level of income the country is converging to, $E\left[\eta_{i} y_{i, t-2 \tau}\right]$ will generally be positive. Hence, omission of the individual effect induces an upward bias in the estimate of beta in equation (2). This translates into a downward bias in the estimate of the convergence coefficient, i.e. the rate at which the economy converges to the steady state. Intuitively, countries with high individual effects will have high levels of steady-state income. Because steady states differ, a country with a high observed income is not necessarily closer to its steady-state than a country with a relatively low observed income. Hence, it will not necessarily grow at a slower rate. If we don't fully control for differences in steady-states we will tend to explain the lack of a strong negative correlation between income levels and growth rates as the result of slow convergence.

The second criticism has to do with the issue of endogeneity. In most specifications of the model, at least a subset of the "flow" elements in the vector $W_{i, t}$ is conceptually endogenous. For example, it is reasonable to suppose that the rate of investment in physical capital - a variable included in the great majority of the studies we are discussing - is determined simultaneously with the rate of growth. Although the case is perhaps strongest for narrowly defined economic variables - like the rate of investment in physical and human capital, or the rate of government expenditure - we believe it applies across the board. For example, there is by now both a strong theoretical case and solid empirical support for the view that economic growth affects the population growth rate of an economy, another recurrent righthand-side variable. At a more abstract level, we wonder whether the very notion of exogenous variables is at all useful in a growth framework (the only exception is perhaps the morphological structure of a country's geography).

\section{Panel Regressions}

Panel-data can help solve some of the problems cross-sections fail to address. Barro and Lee (1994a, 1994b), and Barro and Sala- i-Martin (1995, ch. 12), for example, make some progress on the issue of endogeneity. They use a panel in which the time series information is derived by splitting the 
time-period of analysis into two ten-year sub-periods, namely 1965-75 and 1975-85. "Stock" variables are, respectively, dated 1965 in the equation for 1965-75 growth, and 1975 for 1975-85 growth. They stack the two crosssections for the two sub-periods, and apply a GLS estimator (to correct for serial correlation) where potentially endogenous variables are instrumented by their lagged values. Hence, their work partially corrects the endogeneity problem we found in cross-section work. However, their solution is only consistent under the assumption of "random" individual effects, i.e. individual effects that are correlated over time but not with the other regressors. The problem is that, as we showed above, the presence of a lagged dependent variable necessarily makes the random-effect assumption invalid. Hence, the GLS estimator induces a contemporaneous correlation between the error term and the right-hand-side variables. Thus, while correcting for some of the endogeneity, these contributions fail to deal with our other criticism; namely, omitted-variable bias and inconsistency associated with correlated country-effects.

The opposite is true for the papers by Knight, Loayza and Villanueva (1993), Loayza (1994), and Islam (1995): whereas these studies are the only panel-data contributions (that we are aware of) that address the question of correlated individual effects, they totally ignore the issue of endogeneity. These contributions employ an estimation procedure proposed by Chamberlain (1984), and generally referred to as the "П-matrix" approach. This method is based on a series of transformations of equation (2) that eventually leads to the estimation of a reduced form in which, for each period, a cross-section of income levels is regressed on all the explanatory variables in all periods. For example, for period $s$, the procedure calls for a least-square estimation of: ${ }^{5}$

$$
y_{i, s}=\gamma+\pi_{s 1} W_{i, 1}+\ldots+\pi_{s t} W_{i, t}+\ldots+\pi_{s T} W_{i T}+\epsilon_{i, s}
$$

The structural parameters are then retrieved via minimum distance, exploiting the restrictions imposed on the reduced-form parameters by the transformations leading to (4). Clearly, this method is only valid if all the variables in $W_{i, t}$ can be assumed strictly exogenous. In particular, if any of the regressors is only predetermined, there will necessarily be contemporaneous correlation between explanatory variables and error terms in the reducedform estimation phase. ${ }^{6}$ Clearly, the ensuing inconsistency will carry over to the minimum distance parameters.

\footnotetext{
${ }^{5}$ For ease of exposition, equation (4) represents the reduced form of the $\Pi$-matrix method for the special case in which $W_{i, t}$ is scalar.

${ }^{6}$ Strict exogeneity implies $E\left(W_{i, t} \epsilon_{i, s}\right)=0$ for every $s$ and every $t$. Predeterminacy implies that the above relation only holds for $s \geq t$.
} 
In light of our discussion above, there is a strong a priori case for expecting the assumption of strict exogeneity to be violated in these regressions. In particular, the П-matrix studies we are discussing include the investment rate and the population growth rate among the regressors. However, our case turns out to be much stronger than implied by a priori reasoning alone. In Sections 3 and 4 respectively we discuss and perform a statistical test of the hypothesis that the regressors employed by Knight, Loayza and Villanueva, and Islam are strictly exogenous. The test leads to a rejection, indicating that our "prior" that estimates relying on exogeneity are inconsistent is indeed supported by the data. ${ }^{7}$

We are aware of no empirical study of the determinants of economic growth that simultaneously addresses the two issues of correlated effects and endogeneity satisfactorily. In particular, our the above overview of the literature leads us to argue that almost all existing cross-country regressions, either based on cross-section, or panel-data techniques, have been estimated inconsistently.

\section{A Consistent Estimator for Growth Regres- sions}

We now provide a brief, intuitive description of an estimator that simultaneously addresses the issues of endogeneity and correlated individual effects discussed in the previous section. The Appendix presents a more technical treatment. We use an application of the generalized method of moments (GMM), proposed by Holtz-Eakin, Newey and Rosen (1988) and Arellano

\footnotetext{
${ }^{7}$ There are two additional shortcomings to the methodology employed by Knight, Loayza and Villanueva, Loayza, and Islam, as applied to growth regressions. First, it only allows for specifications with a limited number of explanatory variables. This is because each additional regressor involves a more than proportional increase in the number of parameters to be estimated. Hence, degrees-of-freedom considerations heavily constrain the range of possible applications. For this reason these authors' contributions are limited to estimations of the Solow model, which involves relatively few right-hand-side variables. The estimator we present in the next section is free of this problem. In particular, we are able to apply it to any "determinants-of-growth" regression. A second problem with the "П-matrix" method as applied to cross-country growth is that its consistency relies on an assumption of homoscedasticity in the error terms. It is commonly held, however, that international data are characterized by heteroscedasticity. Again, this difficulty does not apply to the estimator we present in the next section.
} 
and Bond (1991). This GMM estimator optimally exploits all the linear moment restrictions implied by a dynamic panel data model.

From now on, all variables will be taken as deviations from period means so that we will not need to include time-specific constants. With this reinterpretation of the variables in the growth regression, the terms $\xi_{t}$ drop from equation (2). The first step in the estimation procedure is to eliminate the individual effects via a first-difference transformation: ${ }^{8}$

$$
y_{i, t}-y_{i, t-\tau}=\tilde{\beta}\left(y_{i, t-\tau}-y_{i, t-2 \tau}\right)+\left(W_{i, t-\tau}-W_{i, t-2 \tau}\right) \delta+\left(\epsilon_{i, t}-\epsilon_{i, t-\tau}\right)
$$

Equation (5) allows us to get at the parameters of interest without having to rely on any probabilistic statement concerning the country effect. However, the above relation cannot be estimated directly by a least square procedure for two reasons. First, we still have to deal with the endogeneity of the "flow" variables in $W_{i, t-\tau}$ and $W_{i, t-2 \tau}$. Second, the lagged-dependent variable is now correlated with the composed error term through the contemporaneous terms in period $t-\tau$. Hence, instrumental variables are required. The solution we adopt is to use all of the past values of the explanatory variables as instruments in the regression.

Specifically, we make the following identifying assumptions. First, there is no $\tau$-order serial correlation (i.e. $E\left[\epsilon_{i, t} \epsilon_{i, t-\tau}\right]=0$ ). Second, the "stock" variables in vector $W_{i, t-\tau}$ (i.e. those variables measured at the beginning of the $[t-\tau, t]$ period) are predetermined. Third, the "flow" variables in $W_{i, t-\tau}$ (i.e. those that are measured as an average of the $\tau$ periods from $t-\tau$ to $t-1$ ) are not predetermined for $\epsilon_{i, t}$, but they are predetermined for $\epsilon_{i, t+\tau}$.

The implications of these identifying assumptions can be illustrated easily. They imply, for example, that $y_{i, 0}$ and the stock variables in $W_{i, 0}$ are valid instruments for the equation in which we are estimating $y_{i, 2 \tau}-y_{i, \tau}$ as a function of $y_{i, \tau}-y_{i, 0}$ and $W_{i, \tau}-W_{i, 0}$. Moving up one period, we can use $y_{i, 0}$, both the stock and the flow variables in $W_{i, 0}, y_{i, \tau}$, and the stock variables

\footnotetext{
${ }^{8}$ In the panel data literature, several transformations, other than first-differencing, have been suggested to eliminate the individual effects. For instance, the so-called fixedeffects, or within, estimator takes deviations with respect to individual means. However, direct estimation of a fixed-effect regression in the context of a dynamic panel data model would lead to inconsistent estimates. This is the case because, by construction, the lagged dependent variable is correlated with the mean of the individual errors. Furthermore, in an instrumental-variable framework, this procedure would render invalid any predetermined variable as a possible instrument, leaving only strictly exogenous variables as feasible instruments.
} 
in $W_{i, \tau}$ in the regression for $y_{i, 3 \tau}-y_{i, 2 \tau}$, and so on. ${ }^{9}$ The GMM procedure we describe in the appendix allows us to optimally exploit these identifying conditions.

It is clear that the GMM framework deals consistently (and efficiently) with the estimation problems we emphasized in Section 2. However, this consistency critically hinges upon the identifying assumption that lagged values of income and the other explanatory variables are valid instruments in the growth regression. As we have mentioned, a crucial necessary condition in this respect is the lack of $\tau$-order serial correlation in the errors, $\epsilon_{i, t}$, of the equation in levels. We use five- year intervals, so that in our regressions $\tau$ is 5 .

To address these concerns, in Sections 4 and 5 estimation results are complemented by a battery of specification tests (also developed by Arellano and Bond, 1991). ${ }^{10}$ In particular, we start by performing a Sargan test of overidentifying restrictions. This test is based on the sample analog of the moment conditions exploited in the estimation process, and evaluates the overall validity of the set of instruments. Next, we present two tests of the null hypothesis of no serial correlation in the errors in levels. One test is based on the difference between the Sargan statistic described above, and the one obtained by re-estimating (5), dropping all the moment conditions that would be invalid if the errors in levels were fifth-order serially correlated. The second is a test of the hypothesis that the errors in the differenced equation are not tenth-order serially correlated. As we show in the Appendix, this is a necessary condition for the errors in level to be fifth-order uncorrelated. This test is labelled $m_{2}$ in the Tables below. The Sargan, and the DifferenceSargan statistics are distributed chi-square under the null hypothesis, while $m_{2}$ is standard normal. ${ }^{11}$

Our procedure relies on rather weak predeterminacy assumptions about the explanatory variables. This feature allows us to escape the potential endogeneity bias we discussed in the previous section. This distinguishes our

\footnotetext{
${ }^{9}$ In fact, this is similar to what Barro and Lee $(1994 \mathrm{a}, 1994 \mathrm{~b})$ did for the equations in levels. However, as we mentioned above, their solution is not appropriate in the presence of correlated individual effects. In addition, they only instrument for some of their right hand side variables.

${ }^{10}$ Further details are provided in the Appendix.

${ }^{11}$ Arellano and Bond (1991) analyze the power of these tests. Assuming a correlation of 0.3 between $\epsilon_{i, t}$ and $\epsilon_{i, t-\tau}$, and using $5 \%$ as the level of significance, they show that the Difference-Sargan and the $m_{2}$ statistics reject in $70 \%$ and $92 \%$ of the cases, respectively. Since in all of our applications we can never reject the null of no serial correlation, it seems unlikely that we are systematically committing type 2 errors.
} 
study from the "П-matrix" panel-data studies by Knight, Loayza and Villanueva (1993), Loayza (1994) and Islam (1994). As argued above these papers involve a consistent treatment of the individual effect, but require an assumption of strict exogeneity of the vector $W_{i, t}$. Notice that, under strict exogeneity, all leads and lags of the explanatory variables become valid instruments for our GMM procedure.

Indeed, strict exogeneity implies that the estimates obtained in the above mentioned studies are asymptotically equivalent to those that would be obtained through our GMM estimator if all leads and lags of the explanatory variables were used as instruments. ${ }^{12}$ The implication is the following: if strict exogeneity is violated, the $\Pi$-matrix estimates are inconsistent, while our GMM regressions are consistent. If strict exogeneity is not violated, then both approaches lead to consistent estimates, but ours is less efficient.

This suggests a natural way of testing the strict exogeneity assumption. Namely, we perform a Hausman test comparing our basic GMM estimates to those obtained adding current and future values of $W_{i, t}$ to the set of instruments. If the test rejects the null hypothesis that the two estimates are not significantly different, then the results obtained by the $\Pi$-matrix method are inconsistent. ${ }^{13}$

\section{Testing the Solow Model}

\section{Estimating the Solow Model}

In this section we apply the estimation procedure described above to the basic neoclassical growth model, developed by Solow (1956) and Swan (1956). Our agenda is twofold. First, we want to find out quantitatively how important are the econometric issues we stressed in the previous two sections. We accomplish this by comparing our new, consistent estimate of the Solow model to other estimates that follow procedures prone to omitted variable and/or endogeneity bias. We find that the impact of the correction is striking. Second, we use our estimates to test whether the implications of the model are borne out by the data. Our tests unambiguously reject both the textbook and the augmented version of the Solow model.

\footnotetext{
${ }^{12}$ More precisely, this requires the additional hypothesis of homoscedasticity.

${ }^{13} \mathrm{~A}$ final concern for the robustness of our findings is the role of measurement error. In the Appendix we provide evidence that our results are not significantly affected by measurement error.
} 
The Solow model assumes an aggregate production function, with arguments effective labor and the stock of capital. Technological progress, population growth and capital depreciation take place at constant, exogenous rates. The economy is closed. Finally, and most importantly, there is an exogenous and constant rate of saving. It is well known that this model (with Cobb-Douglas technology) leads to the following approximation of the behavior of a country's growth rate in a neighborhood of the steady state: ${ }^{14}$

$$
\begin{aligned}
\ln \left(Y_{i, t}\right)-\ln \left(Y_{i, t-\tau}\right)= & -\left(1-e^{-\lambda \tau}\right) \ln \left(Y_{i, t-\tau}\right)+ \\
& \left.+\left(1-e^{-\lambda \tau}\right) \frac{\alpha}{1-\alpha}[\ln (s)-\ln (n+g+d)]+\eta_{i}+\epsilon_{\alpha, t,}\right)
\end{aligned}
$$

where

$$
\lambda=(n+g+d)(1-\alpha)
$$

In equations (6) and (7), $n$ is the population growth rate, $g$ is the rate of labor-augmenting technological progress, $d$ is the rate of depreciation of physical capital, $\alpha$ is the share of capital in total output, and $s$ is the saving rate. $\lambda$ is called the convergence rate, in that it measures the speed at which a country's output converges to its steady state level.

Mankiw, Romer and Weil (1992), Knight, Loayza and Villanueva (1993), Loayza (1994) and Islam (1995) perform tests of the Solow model based on an estimate of the reduced form (6). Using ordinary least squares for a cross-section of countries, Mankiw, Romer and Weil reject the model's restrictions. Instead, based on the panel-data estimator proposed by Chamberlain (1984), the growth model with exogenous savings is found to be consistent with the data in the other three contributions. Equation (6), however, is clearly a specialization of (1). In Section 2 we explained why the growth estimates in those papers should be expected to be unreliable. Hence, we repeat tests similar to those in the literature, building on consistent estimates of (6) as described in Section 3.

We use international panel-data from Summers and Heston (1991), as made available by Barro and Lee (1994c). In particular, we focus on a subsample of 97 countries selected by Barro and Lee (1994a) for their growth regressions. ${ }^{15}$ Time is measured in years and, in our regressions, $\tau$ is 5 . We focus on the same time span used in previous studies of the Solow model,

\footnotetext{
${ }^{14}$ See, e.g., Barro and Sala-i-Martin (1995, ch.1). For a derivation taking into account the country-effect, see Knight, Loayza and Villanueva (1993).

${ }^{15}$ Their criterion for selection is the availability of the data, for the particular specification they propose. Since we are going to adopt a similar specification in Section 5, we will be limited to the same sample, there. In order to maintain comparability of results within the paper, we choose to adopt the same sample definition in this section as well.
} 
namely 1960 to 1985. Since data at 5-year intervals are missing for some quinquennia for some countries, we modified the estimator discussed above to accommodate unbalanced-panel data. By doing this, we are able to use all 97 countries in the sample, thereby avoiding potential sample-selection bias induced by data availability. ${ }^{16}$

In our regressions, output is measured by GDP per-capita at constant, 1980 international prices. The saving rate at time $t-\tau$ is proxied by the ratio of real domestic investment to GDP, taken as an average over the 5 years preceding $t . n_{i, t-\tau}$ is the average population growth rate between $(t-5)$ and $(t-1)$. Finally, we follow Mankiw, Romer and Weil (1992) in choosing 0.05 as a reasonable assessment of the value of $(g+d)$. However, we also tried - as a robustness check - the alternative measure 0.07. There was no appreciable difference in results.

We start by applying our estimator to an unrestricted version of (6). That is, we allow the coefficients on $\ln (s)$ and $-\ln (n+g+d)$ to differ. The regression yields (standard errors in parenthesis):

$$
\ln \left(Y_{i, t}\right)-\ln \left(Y_{i, t-5}\right)=-0.473 \ln \left(Y_{i, t-5}\right)+0.0748 \ln (s)-0.474 \ln (n+g+(8)
$$

The coefficient on lagged output has the expected negative sign, and is strongly significant. So are the coefficients on the investment rate and the rate of population growth, which also are signed in a manner consistent with the Solow model. By inspection of equation (6) it is clear that an estimate for $\lambda$ can be recovered from the coefficient on lagged output. This implied value of the convergence rate is 0.128 .

The first row in Table 1 reports this, as well as other estimates of the convergence coefficient obtained using different estimation procedures. ${ }^{17}$ Column MRW reproduces the value of $\lambda$ implicitly found by Mankiw, Romer and Weil (1992). ${ }^{18}$ Clearly, there is a striking difference in results: our estimate of the convergence coefficient is approximately 20 times larger than

\footnotetext{
${ }^{16}$ We should say, however, that in our case balanced-panel estimation leads to results that are qualitatively similar to those in the unbalanced panel.

${ }^{17}$ Due to the difference in time intervals featured in the different studies, the coefficients in (8) are not directly comparable across papers. Hence, we only report those results of the other estimations that lend themselves to direct comparison.

${ }^{18}$ Besides the different estimation procedure, there are a number of other differences between the empirical analysis of Mankiw, Romer and Weil and that of this paper. First, they use data from Summers and Heston (1988), rather than the updated version of the data employed here. Second, for the estimates reported in the first column of Tables 1 and
} 
Table 1: Textbook Solow Model

\begin{tabular}{|c|c|c|c|c|}
\hline & MRW & OLS & KLV & This Paper \\
\hline $\begin{array}{c}\lambda \text { unrestricted } \\
\text { (s.e.) }\end{array}$ & 0.00606 & 0.00621 & 0.0626 & 0.128 \\
$(0.00182)$ & $(0.00219)$ & $(0.0124)$ & $(0.030)$ \\
\hline $\begin{array}{c}\delta_{1}+\delta_{2}=0 \text { test } \\
\text { (p- value) }\end{array}$ & & -0.398 & 0.798 & -2.549 \\
\hline $\begin{array}{c}\lambda \text { restricted } \\
\text { (s.e.) }\end{array}$ & & $(0.691)$ & $(0.372)$ & $(0.011)$ \\
\hline $\begin{array}{c}\text { implied } \alpha \\
\text { (s.e.) }\end{array}$ & & $(0.005802)$ & 0.0652 & 0.135 \\
\hline countries & 98 & $0.0121)$ & $(0.055)$ \\
\hline observations & 98 & 4757 & 0.335 & 0.104 \\
& & 97 & 98 & 97 \\
\hline
\end{tabular}

Note: Colums labelled MRW and KLV reproduce results reported, respectively, in Mankiw, Romer and Weil (1992, Table IV), Knight, Loayza and Villanueva (1993, Table 1). Column OLS reports results from a pooled, ordinary least squares regression. The last column corresponds to a generalized method of moments estimate.

in the MRW cross-section. In the two intermediate columns we try to identify the sources of this difference.

The column OLS estimates convergence applying ordinary least squares to a pooled regression of our panel. The estimated $\lambda$ is the same, up to three decimal figures, as the one found by Mankiw, Romer and Weil using the cross-sectional approach. This indicates that it is not the mere breaking up of the 25 year interval into shorter sub-periods that drives our results. This is important because a potential problem of estimating growth regressions with

3, they use a sub-sample of 98 countries that only intersects the Barro and Lee (1994a) sample. Third, they measure population growth by the rate of growth in the workingage population, rather than total population. Remarkably, however, when we apply their estimator (ordinary least squares, 1960-85 cross-section) to our data and sample, we find that the impact of the three differences above is negligible relative to the impact of the difference in empirical methodology. In particular, the implied convergence coefficient from a cross-section à la Mankiw, Romer and Weil, with our data, is 0.008. By comparing this with the corresponding estimates reported in the first and last columns of Table 1, it is clear that the change in results attributable to the difference in samples is dwarfed by the one attributable to the difference in method. 
panel data is that the presence of business cycles may induce upward bias in the convergence coefficient. The result in column OLS seems to indicate that this effect is not important. ${ }^{19}$

The next column reports the implied convergence coefficient according to Knight, Loayza and Villanueva (1993), that we take as representative of the three papers using the $\Pi$-matrix approach. ${ }^{20}$ As we argue in Section 2 , the estimation procedure used in these papers involves a correct treatment of the correlated individual effect. However, this procedure fails to address the other major potential flaw in growth empirics, i.e. the endogeneity of the explanatory variables. Hence, we regard the change in results from columns MRW and OLS to column KLV as a measure of the role of the inappropriate treatment of correlated country-specific effects in biasing the Mankiw, Romer and Weil (1992) results. On the other hand, the difference between column KLV and the one presenting our GMM estimates captures the role of endogeneity in the explanatory variables.

These comparisons make it clear that the country-specific effect is important, but it is not nearly the end of the story. In particular, the correction for endogeneity accounts for approximately one-half of the difference between our estimate and Mankiw, Romer and Weil's. We now turn to assessing the growth-theoretic implications of our finding.

\section{Two Tests of the Solow Model}

It is clear from equation (6) that one possible test of the Solow model is a test of the restriction that the coefficients on $\ln (s)$ and $\ln (n+g+d)$ (say $\delta_{1}$ and

\footnotetext{
${ }^{19}$ An additional reason why we believe our results may be immune from bias generated by business cycle phenomena is that we estimate a regression in deviations from period means. This is equivalent to using time dummies. Kraay and Ventura (1995) show that business cycles are highly correlated internationally. Hence, we argue that the bulk of the short-run fluctuations, i.e. the component that co- -moves world-wide, is controlled for in our estimates. Finally, the specification tests we present at the end of the section indicate no evidence of cycle effects.

${ }^{20}$ The results in Loayza (1994) and Islam (1995) are very similar.
} 
$\left.\delta_{2}\right)$ are opposite in sign and equal in absolute value ${ }^{21}$. The estimates reported in equation (8), however, do not seem to accord with this prediction. The second row in Table 1 reports results for a formal test of this hypothesis, both for our procedure and, when available, for others. Our test result implies a clear rejection of the model's restriction at the 0.05 significance level. This is in sharp contrast with test results falling in the acceptance region in Knight, Loayza and Villanueva (1993), and in the pooled OLS regression. ${ }^{22}$

A second test of (the joint hypothesis of Cobb-Douglas production function and) the Solow model can be obtained by re-estimating (6), imposing the restriction that savings and population growth enter as a difference. This restricted regression is just identified in the parameters of interest $\lambda$ and $\alpha$. Since $\alpha$ measures the share of physical capital in income, its estimated value should be approximately $1 / 3$.

When we estimate the restricted regression the result is:

$$
\ln \left(Y_{i, t}\right)-\ln \left(Y_{i, t-5}\right)=\quad-0.49 \ln \left(Y_{i, t-5}\right)+0.0566[\ln (s)-\ln (n+g+d)[9)
$$

The third and fourth rows of Table 1 show values respectively of the convergence coefficient $\lambda$ and the capital share $\alpha$, implied by the coefficients in (9). The first thing to observe is that estimates of the convergence coefficient are not much affected by restricted, rather than unrestricted, estimation. Hence, the striking impact of correcting for the endogeneity and omitted variable biases is robust to this modification.

As for the implied value of the capital share, we find an implausibly low value of $10 \%$. Hence, the second test rejects the model as well. ${ }^{23}$ Mankiw,

\footnotetext{
${ }^{21}$ More rigorously, this is a test of the joint-hypothesis that the Solow model is correct and the aggregate production function is Cobb-Douglas.

${ }^{22}$ Mankiw, Romer and Weil (1992) do not perform this test. However, they do something similar in estimating an alternative reduced form from the Solow model in which 1985 output is regressed on average savings and average population growth. Again, the model implies that the coefficients are equal in size and have opposite signs. Their test does not reject this restriction.

${ }^{23}$ Besides being inconsistent with the model in itself, the estimated value of $\alpha$ - together with the estimated $\lambda$ - imply an average growth rate of the population of $10 \%$ per year
} 
Romer and Weil (1992) also reject the textbook Solow model because they find implausible values of the capital share. However, in their case $\alpha$ is too high relative to the standard assessment. This is reflected in Table 1 by the $75 \%$ share obtained by the OLS pooled regression. Hence, we both reject, but for opposite reasons. Notice that, due to the relation between $\alpha$ and $\lambda$, we could rephrase the last statement in terms of the convergence rate: Mankiw, Romer and Weil reject because their $\lambda$ is too low, while we reject because it is too high. Finally, notice that the intermediate case -individual effects with strictly exogenous regressors - leads to intermediate results. In Knight, Loayza and Villanueva (1993) the estimated capital share is $1 / 3$, so that the Solow model is not rejected.

\section{Tests of Specification}

In a GMM framework, it is important to check the validity of the moment conditions being exploited. In the present context, lack of first-order serial correlation in the error terms of equations (8) and (9) is the key assumption underlying the consistency of our estimates. Table 2 reports test statistics and p-values for the various specification tests discussed in Section 3 for our two GMM regressions. In light of the test results, the moment conditions underlying our estimator seem to be robustly supported. The hypothesis that the errors in the level equation are serially uncorrelated is not rejected by either the $m_{2}$ or the Difference-Sargan statistics. ${ }^{24}$ Similarly, the Sargan tests for overidentifying restrictions are associated with p-values that place them in the acceptance region.

Note that these test results contribute to our argument that business cycle effects are not biasing our results in a significant way. If such a bias were present, in fact, it would necessarily take the form of first-order serial (from equation (7)). A 10\% average population-growth rate is even more implausible an implication than a $10 \%$ capital share.

${ }^{24} \mathrm{By}$ its construction, the $m_{2}$ test can only be performed when there are at least 3 first-difference equations for each unit in the sample. In our unbalanced panel, however, this requirement is not always met. Hence, we report $m_{2}$ test results for the corresponding balanced-panel. The loss in sample size, however, is minimal (3 countries). 
Table 2: Specification Tests for the Solow Model

\begin{tabular}{|c|c|c|}
\hline & Unrestricted & Restricted \\
\hline Sargan & $\begin{array}{c}25.75 \\
(0.31)\end{array}$ & $\begin{array}{c}19.42 \\
(0.15)\end{array}$ \\
\hline Difference & 12.68 & 12.04 \\
Sargan & $(0.32)$ & $(0.10)$ \\
\hline$m_{2}$ & 0.359 & 0.224 \\
& $(0.72)$ & $(0.83)$ \\
\hline Hausman & 15.24 & 5.50 \\
& $(0.00)$ & $(0.06)$ \\
\hline Countries & 97 & 97 \\
\hline Observations & 382 & 382 \\
\hline
\end{tabular}

Note: p-values in parenthesis.

correlation of the level equation. By rejecting first-order serial correlation in general, our tests also reject it for the special case in which the correlation is generated by the cycle.

The fourth row of Table 2 reports Hausman tests for the hypothesis that the explanatory variables are strictly exogenous. In the unrestricted regression this test leads to a strong rejection. The rejection has two kinds of implications. First, notice that the fundamental assumption of the Solow model is that the investment rate (as well as the rate of population growth) is exogenous. Hence, the fact that we uncover strong evidence of endogeneity of the variables on the right-hand-side of (8) is itself a rejection of the model. This evidence - already implied by the dramatic effects on estimation results obtained by dropping the strict exogeneity assumption, as seen in Table 1 is here complemented by the results of the Hausman test.

Second, the assumption that the explanatory variables are strictly exogenous plays a crucial role in the estimates that use the $\Pi$-matrix approach. Hence, as we anticipated in Section 2, the Hausman-test results lend further support to our "prior" that the results of papers using this approach 
are asymptotically inconsistent.

\section{The Augmented Solow Model}

After rejecting the standard Solow model, Mankiw, Romer and Weil (1992) estimate an augmented version in which the production function also includes the stock of human capital. Their very large implied estimate of $\alpha$ suggests that employing a broader concept of capital may make the Solow model look better. Indeed, they find that the augmented model delivers extremely reasonable results. Since we reject the basic model because it implies too low, rather than too high, a share of capital, it seems highly unlikely that Mankiw, Romer and Weil's solution (doubling capital) will work in our case. However, we now briefly report the results of performing such an experiment using the generalized method of moments estimator.

In the augmented model human capital is accumulated by investing a constant fraction, $s^{h}$, of output in human-capital-enhancing activities (the rate of investment in physical capital is now $s^{k}$ ). In the analysis that follows, we proxy this variable by a country's secondary-enrollment rate, as provided by Barro and Lee (1994c). ${ }^{25}$ The reduced form becomes: ${ }^{26}$

$$
\begin{gathered}
\ln \left(Y_{i, t}\right)-\ln \left(Y_{i, t-\tau}\right)=-\left(1-e^{-\lambda \tau}\right) \ln \left(Y_{i, t-\tau}\right)+\left(1-e^{-\lambda \tau}\right) \frac{\alpha}{1-\alpha-\gamma}\left[\ln \left(s^{k}\right)-\ln (n+g+d)\right] \\
+\left(1-e^{-\lambda \tau}\right) \frac{\gamma}{1-\alpha-\gamma}\left[\ln \left(s^{h}\right)-\ln (n+g+d)\right]+\eta_{i}+\epsilon_{i, t}
\end{gathered}
$$

where $\gamma$ is the share of human capital in output, and the convergence rate $\lambda$ is accordingly modified as:

$$
\lambda=(n+g+d)(1-\alpha-\gamma)
$$

As before we can perform two tests of this model. In the first one, we estimate an unrestricted version of (10), i.e. we allow for free coefficients on the two investment variables and the demographic variable. The test is then

\footnotetext{
${ }^{25}$ This introduces a further deviation from Mankiw, Romer and Weil (1992), who use an alternative measure of investment in education. See however, footnote 18.

${ }^{26}$ See Mankiw, Romer and Weil (1992).
} 
based on the difference from zero of the sum of these coefficients (indicated $\delta_{1}+\delta_{2}+\delta_{3}=0$ in Table 3). Alternatively, one can run a restricted regression. For such a regression, $\lambda, \alpha$ and $\gamma$ are just identified, and one can determine whether their estimates are consistent with their economic interpretation under the Solow model. Table 3 reports the available results.

Table 3: Augmented Solow Model

\begin{tabular}{|c|c|c|c|c|}
\hline & MRW & OLS & KLV & This Paper \\
\hline $\begin{array}{c}\lambda \text { unrestricted } \\
\text { (s.e. })\end{array}$ & $\begin{array}{c}0.0137 \\
(0.0019)\end{array}$ & $\begin{array}{c}0.0106 \\
(0.0028)\end{array}$ & $\begin{array}{c}0.0391 \\
(0.0127)\end{array}$ & $\begin{array}{c}0.0790 \\
(0.0184)\end{array}$ \\
\hline $\begin{array}{c}\delta_{1}+\delta_{2}+\delta_{3}=0 \text { test } \\
(\text { p-value })\end{array}$ & $(0.400)$ & $\begin{array}{c}0.210 \\
(0.410)\end{array}$ & $\begin{array}{c}12.31 \\
(0.000)\end{array}$ & $\begin{array}{c}-0.169 \\
(0.430)\end{array}$ \\
\hline $\begin{array}{c}\lambda \text { restricted } \\
\text { (s.e.) }\end{array}$ & 0.0142 & 0.0107 & & 0.0679 \\
$(0.0019)$ & $(0.0027)$ & & $(0.0206)$ \\
\hline $\begin{array}{c}\text { implied } \alpha \\
\text { (s.e.) }\end{array}$ & 0.480 & 0.496 & & 0.491 \\
\hline $\begin{array}{c}\text { implied } \gamma \\
(\text { s.e. })\end{array}$ & $0.070)$ & $(0.077)$ & & $(0.114)$ \\
\hline countries & 98 & 0.180 & & -0.259 \\
$(0.050)$ & $(0.054)$ & & $(0.124)$ \\
\hline observations & 98 & 479 & 490 & 377 \\
\hline
\end{tabular}

Note: Columns MRW and KLV reproduce results reported, respectively, in Mankiw, Romer and Weil (1992, Tables V and VI) and Knight, Loayza and Villanueva (1993, Table 2). Column OLS reports results from a pooled, ordinary least squares regression. The last column corresponds to a generalized method of moments estimate.

As in Knight, Loayza and Villanueva (1993), including the proxy for investment in human capital causes the estimated convergence coefficient to drop sharply. ${ }^{27}$ Our estimates, however, remain several orders of magnitude greater than Mankiw, Romer and Weil's. Also, the relative contribution of

\footnotetext{
${ }^{27}$ The results on the augmented Solow model from Knight, Loayza and Villanueva (1993) should be interpreted with caution. Because they can only obtain an implied estimate of $\lambda$ when using a time-invariant measure of investment in human capital, the authors employ a mixed panel-cross-section technique whose interpretation in terms of the Solow model
} 
omitted variable bias and endogeneity in explaining this difference is approximately unchanged. Again, there is no appreciable difference between the two OLS procedures (cross-section and panel).

As for the tests of the theory, notice that our unrestricted regression does not lead to rejection of the hypothesis that the three coefficients other than the one on lagged output sum to zero. However, an unambiguous rejection is represented by the estimate of the share of human capital implied by the restricted regression, which is negative, large in absolute value, and strongly significant. We interpret this finding as clear evidence against the augmented Solow model. ${ }^{28}$ Notice that, instead, the OLS regressions provide fairly reasonable estimates of the two capital shares. This is one of the results that lead Mankiw, Romer and Weil (1992) to accept the augmented Solow model. The specification-test results for the augmented model (available from the authors) are broadly consistent with those we report for the textbook version.

In sum, our results in this section indicate that: (i) the estimation issues raised in this paper are important: correcting for the biases that plague standard growth empirics leads to dramatic changes in results; (ii) both the assumptions and the implications of the textbook Solow model are inconsistent with the evidence we uncover; (iii) also the augmented version of the model does not withstand empirical testing. In the next section we therefore abandon the restrictive framework of the Solow model and look at more general formulations.

\section{$5 \quad$ Estimating Convergence}

Having rejected the specific functional form associated with the Solow-Swan neoclassical growth model, we want to use a more general specification. We is not transparent. Dehejia (1994), however, repeats the experiment with an alternative, time-varying proxi for human capital investment, and obtains results similar to those in the KLV column of Table 3.

${ }^{28} \mathrm{In}$ light of this result, the non-rejection in the earlier test can be attributed to high standard errors in the unrestricted regression. 
apply the estimator described in Section 3 to a set of cross-country growth regressions à la Barro. Taking into account individual effects and the endogeneity of the set of explanatory variables changes several of the results obtained in the previous literature. In particular, interpreting the coefficient on lagged output as reflecting the speed of conditional convergence indicates that this parameter is about ten percent per year for a wide range of specifications.

We follow standard practice, and regress the rate of growth of real per-capita-GDP on two sets of variables. First, we consider beginning-ofperiod levels of state variables, which account for the economy's initial position. Second, we include a set of control variables that capture differences in steady-states across countries. This specification is consistent with a variety of neoclassical growth models that accept as a solution a log-linearization around the steady-state of the form ${ }^{29}$

$$
\ln \left(\hat{Y}_{t}\right)-\ln \left(\hat{Y}_{0}\right)=-\left(1-\mathrm{e}^{-\lambda t}\right) \ln \left(\hat{Y}_{0}\right)+\left(1-\mathrm{e}^{-\lambda t}\right) \ln \left(\hat{Y}^{*}\right)
$$

where $\hat{Y}_{t}$ is GDP per effective worker at time $t, \hat{Y}^{*}$ is its steady-state value, and $\lambda$, as before, is the convergence rate.

As in the previous section, we consider a panel including five 5- year periods from 1960 to 1985, for the Barro and Lee (1994a) sample of 97 countries. We also start by using, as a benchmark, the same set of explanatory variables as in the Barro and Lee study. They include as state variables in each regression the initial level of per-capita GDP, the average number of years of male and female secondary schooling and the logarithm of an index of life expectancy. The first is used to proxy the initial stock of physical capital, while the others are proxies for the initial level of human capital. All state variables are measured at the beginning of each 5-year period. The control variables are the investment ratio (I/GDP), the government consumption ratio (net of education and defense expenses, G/GDP), the logarithm of 1 plus the black market premium (BMP) and the number of revolutions; these

\footnotetext{
${ }^{29}$ See Barro and Sala-i-Martin (1995).
} 
are included as annual average values for each 5 -year period. ${ }^{30}$

Table 4 shows the results. The first column presents the Barro and Lee (1994a) estimates. This is a three stage least squares estimation, in which lagged values of per-capita income, and of the investment and government consumption ratios are used as instruments. As was pointed out in Section 2 , this procedure fails to account for correlated individual effects, leading to inconsistent estimates. The Barro and Lee regression covers the periods 1965-75 and 1975-85, and uses as a dependent variable the average annual growth rate of real GDP per capita for each of these two sub-periods. Since we are going to perform the GMM estimation procedure described in Section 3 using four first-difference equations from 1965 to 1985, we also present, as a transition, a pooled ordinary least squares regression in levels using five year periods from 1965 to 1985 . The estimates obtained from this procedure - displayed in column 2 of Table 4 - are inconsistent for the same reason as the Barro and Lee results in column 1.

Given the difference in time intervals, the coefficients on lagged GDP in columns 1 and 2 are not directly comparable. However, we can use the normalization provided by the convergence coefficent, $\lambda$, which is also reported in the table. Both Barro and Lee's and the OLS regression imply values for the convergence coefficient that are consistent with the existing consensus that convergence takes place at a rate roughly in the $2-3$ percent interval. More generally, the comparison of the two columns shows that changing the length of the period covered by each equation of the panel has little effect on most of the coefficients, indicating no evidence of business cycle effects contaminating the estimates. Only the coefficient on revolutions, which appears to be non-significantly different from zero, differs from that used by Barro and Lee. ${ }^{31}$

Columns 3, 4, 5 and 6 report general method of moments estimates for four different specifications of the growth regressions. The regression

\footnotetext{
${ }^{30}$ For an extensive description of these variables and sources see Barro and Lee (1994c).

${ }^{31}$ The coefficients on revolutions are not comparable because Barro and Lee use a time invariant average for the whole period 1965-85, whereas we use the average for each 5-year period.
} 
in column 3 uses the same benchmark specification as those in columns 1 and 2. The major result is that the speed of convergence jumps from below three to almost ten percent per year. The other differences include a reversal in the signs of male and female education, government expenditure, and revolutions, and a loss of significance of the index of life expectancy. These are dramatic changes, and - like the corresponding comparisons in Section 4 they indicate that the sources of inconsistency for which our GMM estimator is designed to control have a strong qualitative and quantitative impact in standard growth empirics.

In Column 4 we drop the life expectancy variable, which was insignificant in Column (3). This causes the number of revolutions to become insignificant. In Column 5, then, we try an alternative measure of political instability: the average number of political assassinations per million population per year. Unlike revolutions, this variable is significant, and has the expected negative sign. In column 6 we add the rate of change of the terms of trade, a variable that captures favorable shocks to external competitiveness. This addition is also successful. At the end of this brief specification search, the convergence rate is again at $10 \%$. Before discussing the economic implications of this high figure, we briefly comment on the other coefficients.

Barro and Lee obtain a significantly negative coefficient on female education, and a significantly positive one on male education. We find the exact opposite. Both results are puzzling because, whereas different models lead to different predictions on the expected sign of the coefficient on the human capital variables, there is no theory that is consistent with different signs for male and female human capital. However, it often has been documented that there is a strong negative relationship between female education and fertility rates, and an equally strong negative relationship between fertility rates and growth rates. ${ }^{32}$ Hence, our interpretation is that the female education variable captures both (positive) fertility effects, and (negative) human capital effects, and the former outweighs the latter. Male education, on the other hand, only represents a human capital effect. Hence, its negative coefficient.

\footnotetext{
${ }^{32}$ See Barro and Sala-i-Martin (1995, ch. 12), and Barro and Lee (1994a)
} 
Another new result is the robustly positive contribution of the government spending ratio, net of military and educational expenditures. A positive role of government spending in growth is predicted by the Barro (1990) model of productive government services. The other results are standard. The positive role of the investment ratio is usually interpreted as capturing the effect of savings on the steady state. The negative sign on the black market premium represents financial repression and other government activities that distort the market allocation mechanism. Political assassinations are the result of social instability and uncertainty about property rights: these factors hinder economic growth. Finally, the terms of trade capture the role of interdependence in the growth process.

Table 5 shows results for the specification tests discussed in Section 3. The Sargan test does not reject the validity of the overidentifying restrictions. The Difference-Sargan test does not reject in either of the four cases the null hypothesis of absence of second order serial correlation in the residuals from the first- difference equation. The same result is obtained using the $m_{2}$ test. In addition, the Hausman test strongly rejects the strict exogeneity of each set of explanatory variables.

\section{Implications for Growth Theory}

Our key result is a convergence speed of about 10 percent per year. This is a high rate of convergence: it implies that the average time an economy spends to cover half of the distance between its initial position and its steady-state is about seven years instead of the thirty implied by convergence rates between two and three percent. As a consequence, most economies will usually be very near to their steady states, and the important differences in per-capita income levels across countries will mainly be explained by differences in their steady-state values.

What is the relatioship between these differences in steady-state output and the country-specific effects? Figure 1 plots estimates of each country's individual effect against its output level in 1985 (both as deviations 
from the international average) ${ }^{33}$ Because countries are close to their steady states, the latter is a rough estimate of the steady state (relative to the international average). The Figure reveals a strikingly high correlation between country effects and output levels. We now discuss a possible interpretation of this finding. ${ }^{34}$

As we pointed out in Section 2, it is natural to interpret the idiosyncratic component as representing international differences in the parameters characterizing the aggregate production function. Some authors argue that cross-country differences in the aggregate production function should be ruled out a priori, because knowledge of how capital and labor can be most efficiently combined to generate output flows freely across borders. Other authors object to this "public-good" view of technology, and stress excludability (through patent laws and secrecy), learning by doing, organizational capital, and a variety of sources of empirical evidence, to argue that the available set of technologies differs substantially across countries. This second view is reinforced if one adopts a broader interpretation of the aggregate production function that recognizes the role of societal norms, custom, political institutions and legal systems in determining the overal efficiency with which a society functions. ${ }^{35}$ Needless to say, the large role of individual effects we uncover tends to support the view that international differences in technology are important. ${ }^{36}$

One remaining problem is the need to explain the large and persistent differences in growth rates (as opposed to output levels) across countries.

\footnotetext{
${ }^{33}$ See the Appendix for the procedure by which we obtain these estimates of $\eta_{i}$.

${ }^{34}$ The high correlation depicted in Figure 1 is a total correlation, in the sense that determinants of a country steady-state output level, other than the country effect, are not partialled out. These other determinats are likely to be correlated with the country effect. Hence, it would be misleading to interpreting the relationship in Figure 1 as describing the degree to which country effects "explain" differences in incomes across countries.

${ }^{35} \mathrm{It}$ would be beside the point to survey this debate any further here. See, for an example, Mankiw (1995) and the comments that follow, as well as the literature cited therein.

${ }^{36}$ Differences in (broad) production functions also help explain other "puzzles" of growth theory, such as "why capital does not flow from rich to poor countries", or, equivalently, why large international differences in rates of return do not appear to exist.
} 
Because our high rate of convergence implies that countries are close to the steady state, it is difficult to appeal to transitional dynamics to explain why some countries grow much faster than others. A tentative solution is as follows. As discussed above, in the general specification of growth regressions a linear combination of the observable explanatory variables (other than lagged income) and the individual effect $\left(W_{i, t-\tau} \delta+\eta_{i}\right.$ in equation 1$)$ is intended as a proxi for steady-state output $\left(\ln \left(\hat{Y}^{*}\right)\right.$ in equation 12$)$. By definition $\eta_{i}$ is constant, but elements of $W_{i, t-\tau}$ can (and do) vary over time. Hence, we can interpret these shifts in the observable explanatory variables as proxies for shifts of the steady state. Such shocks to the steady state set the transition process in motion again. Countries with exceptionally high growth rates are countries that experienced repeated shifts "forward" in the steady state during the sample period. ${ }^{37}$

We conclude with two observations that try to single out, within the class of neoclassical models that predict convergence, the particular variant that seems most likely to have generated the data. The first observation is that high convergence rates are typically associated with open economy versions of the neoclassical model. In particular, Barro and Sala-i-Martin (1995, ch. 3) argue that a model combining collateral constraints to international borrowing, finite lifetimes, and adjustment costs would predict in an open economy setting - rates of convergence that, albeit finite, are higher than those implied by closed economy models. Accordingly, the high rate of convergence found in this paper favors open economy versus closed economy versions of the neoclassical growth model. The significant effect of international trade measures, reported in Table 4, also supports this view.

The second point is that, as repeatedly noted since Mankiw, Romer and Weil (1992), it is difficult to reconcile high speeds of convergence with high values of the share of capital. ${ }^{38}$ In Section 4 we have seen how this

\footnotetext{
${ }^{37}$ Neoclassical theory requires these shifts to be perceived as permanent by the representative consumer. It should be noted that our results are also consistent with a completely different theoretical framework. In the two-sector, open economy model analyzed by Ventura (1995) a strong negative association between GDP levels and growth rates in a cross-section can be associated with permanent differences in international growth rates. ${ }^{38}$ See the discussion in Mankiw (1995). Of course, the argument is usually used in the
} 
problem operates in the context of the Solow model. We can now provide an open economy example, based on the Barro, Mankiw and Sala-i-Martin (1995) model with collateral constraints. As with any variant of the Ramsey framework, a log-linear approximation around the steady-state delivers a formula for the convergence rate, as a function of the taste and technology parameters. ${ }^{39}$ If the share of capital is $75 \%$ - corresponding to a broad definition including physical and human capital - this formula implies, for benchmark values of the other parameters, convergence rates between $1.5 \%$ and $3 \%{ }^{40}$ In order to be consistent with our new estimate of a $10 \%$ convergence rate the formula requires a share of capital on the order of $30 \%$, the standard figure associated with non-augmented versions of the growth model.

In summary, we find that countries converge to the steady state at a rate of approximately 10 percent. Differences in technology appear to play a large role in explaining international differences in per capita income levels. Our findings tend to support open economy versions of the neoclassical growth model. There is no evidence that human capital enters independently as an input in the aggregate production function.

\section{Conclusions}

In this paper we have criticized existing cross-country empirical research on economic growth, showing that the statistical assumptions underlying such other direction, by noting that speeds of convergence in a neighborhood of $2 \%$ are not compatible with the share of capital of 30 percent implied by the standard Solow and Ramsey models respectively.

${ }^{39}$ The formula is

$$
2 \lambda=\left\{\zeta^{2}+4 \frac{(1-\epsilon)}{\theta}(\rho+\delta+\theta g)\left[\frac{\rho+\delta+\theta g}{\epsilon}-(n+g+\delta)\right]\right\}^{1 / 2}-\zeta
$$

where $\rho$ is the rate of intertemporal preference, $\theta$ is the inverse of the intertemporal elasticity of substitution, $\zeta=\rho-n-(1-\theta g)$, and $\epsilon=\eta /(1-\omega)$. In the last expression, $\eta(\omega)$ is the share of capital that cannot (can) be used as collateral for international borrowing.

${ }^{40}$ See Barro and Sala-i-Martin, 1995. 
work are violated. We have suggested that generalized method of moments estimation is immune to the inconsistency problems that invalidate standard techniques. All of our applications to growth of the GMM estimator show that eliminating the sources of inconsistency produces striking effects.

We have presented two sets of results using the consistent estimator. First, we have tested some of the implications of the Solow (1956) model, both in the textbook and in an "augmented" form. Neither of the two versions is consistent with the data.

Second, we have estimated a number of "determinants of growth" regressions. The main result is that a country's GDP per capita converges to its steady state level at a rate of about $10 \%$. We have discussed the theoretical implications of this finding.

Revisiting other data sets with improved techniques may also be fruitful. In particular, regional data sets on the United States, Europe and Japan have been used to study questions similar to those addressed with the Summers and Heston data (see, e.g., Barro and Sala-i-Martin (1992, 1995, ch. 11)). Arguably, to the extent that such regions share similar technologies and tastes, the incorrect treatment of the individual effect may be less serious a source of bias. However, there is no reason to expect endogeneity to be less of a problem in cross-regional relative to cross-country growth. Hence an appropriate estimation procedure is needed.

\section{Appendix}

\section{Dynamic Panel Estimation with GMM}

Rewrite equation (5) as

$$
\triangle y_{i, t}=\triangle X_{i, t} \theta+\triangle \epsilon_{i, t}
$$

where $\theta^{\prime}=\left(\begin{array}{ll}\tilde{\beta} & \delta^{\prime}\end{array}\right), X_{i, t}$ is a $1 \times K$ vector defined as $\left(y_{i, t-\tau} \quad W_{i, t-\tau}\right)$ and $\triangle$ is the difference operator. We have information from period 0 to period $T_{0} \tau$ for the dependent variable, and from period 0 to $T \tau$ for the explanatory variables $\left(T=T_{0}-1\right)$. Hence, we have $T$ equations in differences. In what 
follows, we concentrate on the case $T=4$, which is the case that applies to our regressions.

Consider a partition of the vector $W_{i, t}$ into variables that are predetermined for $\epsilon_{i, t+\tau}$, say $W_{i, t}^{1}$, and variables that are predetermined for $\epsilon_{i, t+2 \tau}$, $W_{i, t}^{2} ; W_{i, t}=\left(W_{i, t}^{1} W_{i, t}^{2}\right)$. Consider the instrument matrix

$$
Z_{i}=\left(\begin{array}{cccccccccccccccccccc}
y_{i, 0} & W_{i, 0}^{1} & 0 & 0 & 0 & 0 & 0 & 0 & 0 & 0 & 0 & 0 & 0 & 0 & 0 & 0 & 0 & 0 & 0 & 0 \\
0 & 0 & y_{i, 0} & W_{i, 0} & y_{i, \tau} & W_{i, \tau}^{1} & 0 & 0 & 0 & 0 & 0 & 0 & 0 & 0 & 0 & 0 & 0 & 0 & 0 & 0 \\
0 & 0 & 0 & 0 & 0 & 0 & y_{i, 0} & W_{i, 0} & y_{i, \tau} & W_{i, \tau} & y_{i, 2 \tau} & W_{i, 2 \tau}^{1} & 0 & 0 & 0 & 0 & 0 & 0 & 0 & 0 \\
0 & 0 & 0 & 0 & 0 & 0 & 0 & 0 & 0 & 0 & 0 & 0 & y_{i, 0} & W_{i, 0} & y_{i, \tau} & W_{i, \tau} & y_{i, 2 \tau} & W_{i, 2 \tau} & y_{i, 3 \tau} & W_{i, 3 \tau}^{1}
\end{array}\right)
$$

Call $M$ the number of columns of $Z_{i}$. Now define the vector of differentiated errors:

$$
\nu_{i}=\left(\epsilon_{i, 2 \tau}-\epsilon_{i, \tau}, \ldots, \epsilon_{i, 5 \tau}-\epsilon_{i, 4 \tau}\right)^{\prime}
$$

The above predeterminacy assumptions, together with the assumption of no $\tau$-order serial correlation, imply that $E\left(Z_{i}^{\prime} \nu_{i}\right)=\mathbf{0}$, where $\mathbf{0}$ is an $M \times 1$ null vector. Thus, $Z_{i}^{\prime} \nu_{i}(\theta)$ is a set of $M$ functions satisfying the orthogonality conditions $E\left[Z_{i}^{\prime} \nu_{i}(\theta)\right]=0$. Hence, Hansens's (1982) results imply that a consistent estimate of $\theta$ can be obtained as

$$
\theta_{j}=\operatorname{argmin}\left(\frac{1}{N} \sum_{i=1}^{N} Z_{i}^{\prime} \nu_{i}\right)^{\prime} A_{j}\left(\frac{1}{N} \sum_{i=1}^{N} Z_{i}^{\prime} \nu_{i}\right)
$$

Where $N$ is the number of countries in the sample, and $A_{j}$ is any symmetric, positive semi-definite matrix of dimension $(M \times M)$. Let us introduce the following notation: $X_{i}=\left[X_{i, 0}^{\prime} \ldots X_{i, T \tau}^{\prime}\right]^{\prime}, y_{i}=\left[y_{i, 0} \ldots y_{i, T \tau}\right]^{\prime}, Z=\left[Z_{1}^{\prime} \ldots Z_{i}^{\prime} \ldots Z_{N}^{\prime}\right]^{\prime}$, $X=\left[\triangle X_{1}^{\prime} \ldots \triangle X_{i}^{\prime} \ldots \triangle X_{N}^{\prime}\right]^{\prime}$ and $y=\left[\triangle y_{1} \ldots \triangle y_{i} \ldots \triangle y_{N}\right]^{\prime} . Z, X$ and $y$ have, respectively, sizes $N T \times M, N T \times K$ and $N T \times 1$. The solution to problem (14) can then be expressed as:

$$
\theta_{j}=\left(X^{\prime} Z A_{j} Z^{\prime} X\right)^{-1} X^{\prime} Z A_{j} Z^{\prime} y
$$

The asymptotic covariance matrix of $\theta_{j}$ is

$$
\Lambda=\left(E\left[Z_{i}^{\prime} X_{i}\right]^{\prime} A_{j}^{*} E\left[Z_{i}^{\prime} X_{i}\right]\right)^{-1} E\left[Z_{i}^{\prime} X_{i}\right]^{\prime} A_{j}^{*} E\left[Z_{i}^{\prime} \nu_{i} \nu_{i}^{\prime} Z_{i}^{\prime}\right] A_{j}^{*} E\left[Z_{i}^{\prime} X_{i}\right]\left(E\left[Z_{i}^{\prime} X_{i}\right]^{\prime} A_{j}^{*} E\left[Z_{i}^{\prime} X_{i}\right]\right)^{-1}
$$

where $A_{j}^{*}$ is the probability limit of $A_{j}$. A consistent estimate of $\Lambda$ is:

$$
\Lambda_{j}=N\left(X^{\prime} Z A_{j} Z^{\prime} X\right)^{-1} X^{\prime} Z A_{j}\left(\sum_{i=1}^{N} Z_{i}^{\prime} \hat{\nu}_{i} \hat{\nu}_{i}^{\prime} Z_{i}\right) A_{j} Z^{\prime} X\left(X^{\prime} Z A_{j} Z^{\prime} X\right)^{-1}
$$


where $\hat{\nu}_{i} \equiv \triangle y_{i}-\triangle X_{i} \theta_{j}$ is an estimate of the differenced errors $\nu_{i}$.

Optimality is achieved if $A_{j}^{*}=E\left[Z_{i}^{\prime} \nu_{i} \nu_{i}^{\prime} Z_{i}\right]$, i.e. the variance-covariance matrix of the moment conditions being exploited. Arellano and Bond (1991) suggest a two- step procedure. In the first step it is assumed that the errors $\epsilon_{i, t}$ are independent and identically distributed, with constant variance $\sigma_{\epsilon}^{2}$. This implies

$$
E\left[\nu_{i} \nu_{i}^{\prime}\right]=\sigma_{\epsilon}^{2}\left[\begin{array}{ccccc}
2 & -1 & 0 & \cdots & 0 \\
-1 & 2 & -1 & \cdots & 0 \\
0 & \ddots & \ddots & \ddots & \ddots \\
0 & \cdots & \cdots & -1 & 2
\end{array}\right] \equiv \sigma_{\epsilon}^{2} H
$$

A first-step estimate of $\theta, \theta_{1}$, is then obtained using $A_{1} \equiv \frac{1}{N} \sum_{i=1}^{N}\left(Z_{i}^{\prime} H Z_{i}\right)^{-1}$ in (15). $\theta_{1}$ is consistent (since $A_{1}$ is positive semi-definite) and asymptotically efficient if the homoscedasticity assumption is correct. In the second stage homoscedasticity is relaxed. Instead, the first-stage estimated errors, $\hat{\nu}_{i}^{1}$, are used to build a consistent estimate of the variance-covariance matrix of the moment conditions. This is then used as a weight matrix in the second stage: $A_{2} \equiv \frac{1}{N} \sum_{i=1}^{N}\left(Z_{i}^{\prime} \hat{\nu_{i}^{1}} \hat{\nu}_{i}^{\prime} Z_{i}\right)^{-1}$.

\section{Tests of Specification}

The Sargan statistic is given by

$$
s=\hat{\nu}^{\prime} Z\left(\sum_{i=1}^{N} Z_{i}^{\prime} \hat{\nu}_{i} \hat{\nu}_{i}^{\prime} Z_{i}\right)^{-1} Z^{\prime} \hat{\nu}
$$

where $\hat{\nu} \equiv\left[\hat{\nu}_{1}^{\prime}, \ldots, \hat{\nu}_{N}^{\prime}\right]^{\prime}$ is a vector of second-stage estimated residuals. The null hypothesis is $E\left[Z_{i}^{\prime} \nu_{i}\right]=0$. Under the null, the asymptotic distribution of $s$ is $\chi_{M-K}^{2}$.

The errors of the differenced equation, $\nu_{i, t}=\epsilon_{i, t}-\epsilon_{i, t-\tau}$, are in general $\tau$ - order serially correlated. ${ }^{41}$ However, they are $2 \tau$-order uncorrelated if the $\epsilon_{i, t}$ are $\tau$-order uncorrelated. Hence, a rejection of the null that the $\nu_{i, t}$ is $2 \tau$-order uncorrelated is equivalent to a rejection of the hypothesis that

\footnotetext{
${ }^{41}$ We rule out the (unlikely) case in which $\epsilon_{i, t}$ is a random walk.
} 
the $\epsilon_{i, t}$ are $\tau$-order incorrelated. Consider the following notation: $\hat{\nu}_{-2_{i}} \equiv$ $\left[\hat{\nu}_{i, 1}, \ldots, \hat{\nu}_{i,(T-2) \tau}\right]^{\prime}, \hat{\nu}_{*_{i}} \equiv\left[\hat{\nu}_{i, 3 \tau}, \ldots, \hat{\nu}_{i, T \tau}\right]^{\prime}, \hat{\nu}_{-2} \equiv\left[\hat{\nu}_{-2_{1}}^{\prime}, \ldots, \hat{\nu}_{-2_{N}}^{\prime}\right]^{\prime}$ and $\hat{\nu}_{*} \equiv$ $\left[\hat{\nu}_{*_{1}}^{\prime}, \ldots, \hat{\nu}_{*_{N}}^{\prime}\right]^{\prime}$. The statistic

$$
m_{2}=\frac{\hat{\nu}_{-2}^{\prime} \hat{\nu}_{*}}{Q}
$$

is an average of the $2 \tau$-order covariances of the differenced equations. $Q$ is the appropriate standardization. $m_{2}$ is standard normal and can be used as a test of the null hypothesis that the differenced errors are not $2 \tau$-order serially correlated.

\section{Measurement Error}

No growth regression is immune to the problem of measurement error. The question is whether our estimation procedure could make the problem worse, relative to standard techniques. The paper presents very strong evidence that the errors in the growth equation are not 5-order serially correlated. Obviously this implies that measurement error, if present, cannot be 5 -order serially correlated.

It is rather simple to show that, with such temporary measurement error, the GMM estimates (like those obtained by the standard literature) tend to overestimate the rate of convergence. However, GMM estimates obtained by dropping the most recent instruments for each equation (for example, dropping $\ln \left(Y_{t-10}\right)$ from the list of instruments for the equation in which $\triangle \ln \left(Y_{i, t}\right)$ appears on the left-hand-side) are consistent. Hence, we reestimate convergence with this smaller set of instruments, and compare the new estimates free of measurement error with those presented in the text. If measurement error is playing a role in upward-biasing our results, the latter should tend to be systematically greater than the former.

Table 6 presents this comparison for the growth regressions presented in Table 4. It is clear that there is no systematic pattern of over-estimation of convergence associated with our GMM estimates. 


\section{Estimation of the Individual Effects}

Define $\bar{x}_{i, t}$ as the deviation from the cross-sectional mean of $x$, i.e. $\bar{x}_{i, t}=$ $x_{i, t}-1 / N\left(\sum_{i} x_{i, t}\right)$. Rewrite equation (2) in deviations from the international mean:

$$
\bar{y}_{i, t}=\tilde{\beta} \bar{y}_{i, t-\tau}+\bar{W}_{i, t-\tau} \delta+\bar{\eta}_{i}+\bar{\epsilon}_{i, t}
$$

Now use the estimates of $\tilde{\beta}$ and $\delta$ from our "preferred" equation (column 6 of Table 4) to obtain estimates of the quantity $\bar{\eta}_{i}+\bar{\epsilon}_{i, t}$ :

$$
\left(\bar{\eta}_{i} \widehat{+}_{i, t}\right)=\bar{y}_{i, t}-\left(\widehat{\widetilde{\beta}} \bar{y}_{i, t-\tau}-\bar{W}_{i, t-\tau} \widehat{\delta}\right)
$$

Finally, obtain estimates of $\bar{\eta}_{i}$ by taking the time- average of the last quantity:

$$
\hat{\bar{\eta}}_{i}=\frac{1}{T} \sum_{t}\left(\bar{\eta}_{i} \widehat{+}_{i, t}\right)
$$

Because the time dimension is small, this is obviously a very rough estimate, and is only intended to give an "order of magnitude" idea of the role of the individual effects. 


\section{References}

Arellano, M. and S. Bond (1991); "Some Tests of Specification for Panel Data: Monte Carlo Evidence and an Application to Employment Equations", Review of Economic Studies, 58, 277-297.

Barro, R.J. (1990); "Government Spending in a Simple Model of Endogenous Growth", Journal of Political Economy, 98, s103-s125.

Barro, R.J. (1991); "Economic Growth in a Cross-section of Countries", Quarterly Journal of Economics, 106, 407-443.

Barro, R.J. and J.W. Lee (1994a); "Losers and Winners in Economic Growth", Proceedings of the World Bank Annual Conference on Development Economics, The World Bank, 267-297.

Barro, R.J. and J. W. Lee (1994b); "Sources of Economic Growth", Carnegie Rochester Conference on Public Policy, 40, 1-46.

Barro, R.J. and J. W. Lee (1994c); Data Set for a Panel of 138 Countries, manuscript, Harvard University.

Barro, R.J. and X. Sala-i-Martin (1991); "Convergence Across States and Regions", Brooking Papers on Economic Activity, no. 1, 107-158.

Barro, R.J. and X. Sala-i-Martin (1992); "Convergence", Journal of Political Economy, 100, 223-251.

Barro, R.J. and X. Sala-i-Martin (1995); Economic Growth, New York: Mc Graw Hill.

Barro, R.J., G.N. Mankiw and X. Sala-i-Martin (1995); "Capital Mobility in Neoclassical Growth Models", American Economic Review, 85, 103-115.

Baumol, W. (1986); "Productivity Growth, Convergence and Welfare: What the Long-Run Data Show", American Economic Review, 76, 1072-1085.

Chamberlain, G. (1984); "Panel Data", in Z. Griliches and M. D. Intrilligator (eds.), Handbook of Econometrics (vol.2), Amsterdam: Elsevier, 1247-1313. 
Dehejia, R. (1994); "Economic Growth - The Role of Human Capital and Country Specific Effects", manuscript.

DeLong, B. (1988); "Productivity Growth, Convergence and Welfare: Comment", American Economic Review, 78, 1138-1154.

DeLong, B. and L. H. Summers (1991); "Equipment Investment and Economic Growth", Quarterly Journal of Economics, 106, 445-502.

Evans, P. (1995); "How to Estimate Growth Regressions Consistently", manuscript.

Holtz-Eakin, D., W. Newey and H. Rosen (1988); "Estimating Vector Autoregressions with Panel Data", Econometrica, 56, 1371-1395.

Islam, N. (1995); "Growth Empirics: A Panel Data Approach", Quarterly Journal of Economics, 110.

King, R. and R. Levine (1993); "Finance and Growth: Schumpeter Might Be Right", Quarterly Journal of Economics, 106, 717-737.

Knight, M., N. Loayza and D. Villanueva (1993); "Testing the Neoclassical Growth Model", IMF Staff Papers, 40, 512-541.

Kormendi, R. and P. Meguire (1985); "Macroeconomic Determinants of Growth", Journal of Monetary Economics, 16, 141-163.

Kraay, A., and J. Ventura (1995); "Financial Market Integration and Economic Fluctuations", manuscript.

Levine, R. and D. Renelt (1992); "A Sensitivity Analysis of Cross-Country Growth Regressions", American Economic Review, 82, 942963.

Loayza, N. (1994); "A Test of the International Convergence Hypothesis Using Panel Data”, Policy Research Working Paper no. 1333, The World Bank.

Maddison, A. (1982); Phases of Capitalist Development, Oxford: Oxford University Press.

Mankiw, N.G. (1995); "The Growth of Nations", Brookings Papers on Economic Activity, (1), 275-326.

Mankiw, G.N., D. Romer and D. Weil (1992); "A Contribution to the Empirics of Growth", Quarterly Journal of Economics, 107, 407-437. 
Sala-i-Martin, X. (1994); "Cross-Sectional Regressions and the Empirics of Economic Growth", European Economic Review, 38, 739-747.

Solow, R. (1956); "A Contribution to the Theory of Economic Growth", Quarterly Journal of Economics, 70, 65-94.

Summers, R. and A. Heston (1988); "A New Set of International Comparisons of Real Product and Price Levels Estimates for 130 Countries, 1950-1985"; Review of Income and Wealth, 1-25.

Summers, R. and A. Heston (1991); "The Penn World Tables (Mark 5): An Expanded Set of International Comparisons 1950-1988"; Quarterly Journal of Economics, 106, 327-368.

Summers, R. and A. Heston (1993); "The Penn World Table (Mark 5.5)", electronic dataset.

Swan, T. (1956); "Economic Growth and Capital Accumulation", The Economic Record, 32, 334-361.

Ventura, J. (1994); "Growth and Interdependence", manuscript. 
Table 4: Growth Regressions

\begin{tabular}{|c|c|c|c|c|c|c|}
\hline \multirow[t]{2}{*}{ Variable } & \multirow{2}{*}{$\begin{array}{c}\text { Barro- Lee } \\
\text { (1) }\end{array}$} & \multirow{2}{*}{$\begin{array}{c}\text { OLS } \\
(2)\end{array}$} & \multicolumn{4}{|c|}{ GMM } \\
\hline & & & (3) & $(4)$ & $(5)$ & $(6)$ \\
\hline \multirow[t]{2}{*}{$\ln y_{t-\tau}$} & $-0.0255^{*}$ & $-0.0228^{*}$ & $-0.0770^{*}$ & $-0.0544^{*}$ & $-0.0652^{*}$ & $-0.0792^{*}$ \\
\hline & $(0.0035)$ & $(0.003)$ & $(0.009)$ & $(0.010)$ & $(0.008)$ & $(0.006)$ \\
\hline \multirow[t]{2}{*}{ male educ. } & $0.0138^{*}$ & $0.0161^{*}$ & $-0.0399 *$ & $-0.00280^{*}$ & $-0.0262^{*}$ & $-0.0181^{*}$ \\
\hline & $(0.0042)$ & $(0.0043)$ & $(0.0080)$ & $(0.0078)$ & $(0.0081)$ & $(0.0065)$ \\
\hline \multirow[t]{2}{*}{ female educ. } & $-0.0092 \ddagger$ & $-0.0123^{*}$ & $0.0604^{*}$ & $0.0315^{*}$ & $0.0315^{*}$ & $0.0298^{*}$ \\
\hline & $(0.0047)$ & $(0.0046)$ & $(0.0100)$ & $(0.0087)$ & $(0.0094)$ & $(0.0070)$ \\
\hline \multirow[t]{2}{*}{ I/GDP } & $0.077^{*}$ & $0.0875^{*}$ & $0.126^{*}$ & $0.101^{*}$ & $0.0972 *$ & $0.151^{*}$ \\
\hline & $(0.027)$ & $(0.0205)$ & $(0.038)$ & $(0.039)$ & $(0.0384)$ & $(0.028)$ \\
\hline \multirow[t]{2}{*}{ G/GDP } & $-0.155^{*}$ & $-0.0533 \dagger$ & $0.299^{*}$ & $0.224^{*}$ & $0.237^{*}$ & $0.162^{*}$ \\
\hline & $(0.034)$ & $(0.0239)$ & $(0.045)$ & $(0.048)$ & $(0.049)$ & $(0.050)$ \\
\hline \multirow[t]{2}{*}{$\ln (1+\mathrm{BMP})$} & $-0.0304^{*}$ & $-0.0288^{*}$ & $-0.0364^{*}$ & $-0.0598^{*}$ & - 0.0491* & $-0.0318^{*}$ \\
\hline & $(0.0094)$ & $(0.0046)$ & $(0.0045)$ & $(0.0070)$ & $(0.0085)$ & $(0.0075)$ \\
\hline \multirow[t]{2}{*}{ revolutions } & $-0.0178 \dagger$ & 0.00206 & $0.0261^{*}$ & 0.00183 & & \\
\hline & $(0.0089)$ & $(0.00489)$ & $(0.0051)$ & $(0.00544)$ & & \\
\hline \multirow[t]{2}{*}{ ln (life expect.) } & $0.0801^{*}$ & $0.0706^{*}$ & -0.00108 & & & \\
\hline & $(0.0139)$ & $(0.0147)$ & $(0.03208)$ & & & \\
\hline \multirow[t]{2}{*}{ assassinations } & & & & & $-0.0789^{*}$ & $-0.0811^{*}$ \\
\hline & & & & & $(0.0044)$ & $(0.0040)$ \\
\hline \multirow[t]{2}{*}{ terms of trade } & & & & & & $0.0566^{*}$ \\
\hline & & & & & & $(0.0179)$ \\
\hline \multirow[t]{2}{*}{ implied $\lambda$} & $0.0294^{*}$ & $0.0242^{*}$ & $0.0972^{*}$ & $0.0635^{*}$ & $0.0789^{*}$ & $0.101^{*}$ \\
\hline & $(0.0040)$ & $(0.0036)$ & $(0.0140)$ & $(0.0141)$ & $(0.0125)$ & $(0.010)$ \\
\hline \multirow{2}{*}{$\begin{array}{l}\text { countries } \\
\text { observations }\end{array}$} & 85 & 91 & 91 & 93 & 93 & 90 \\
\hline & 180 & 357 & 316 & 319 & 319 & 302 \\
\hline
\end{tabular}

Note: The dependent variable is $\left[\ln \left(Y_{i, t}\right)-\ln \left(Y_{i, t-\tau}\right)\right] / \tau . \tau$ is 10 in Column 1, and 5 in Columns 2-6. Column 1 is reproduced from Barro and Lee (1994a, Table 5). ${ }^{*}, \dagger$ and $\ddagger$ indicate that the coefficent is significantly different from 0 at the 1, 5 and $10 \%$ significance level, respectively. Standard errors are in parenthesis. 
Table 5: Tests of Specification

\begin{tabular}{|l|cccc|}
\hline Test & \multicolumn{4}{|c|}{ regression } \\
& $(3)$ & $(4)$ & $(5)$ & $(6)$ \\
\hline Sargan & 67.68 & 55.99 & 55.92 & 58.01 \\
& $(0.136)$ & $(0.173)$ & $(0.175)$ & $(0.264)$ \\
\hline Diff. Sargan & 19.42 & 21.93 & 25.02 & 33.10 \\
& $(0.885)$ & $(0.583)$ & $(0.405)$ & $(0.194)$ \\
\hline $\mathrm{m} 2$ & -0.240 & -0.015 & -0.674 & -0.692 \\
& $(0.811)$ & $(0.988)$ & $(0.500)$ & $(0.489)$ \\
\hline Hausman & 73.41 & 35.73 & 99.14 & 200.7 \\
& $(0.000)$ & $(0.000)$ & $(0.000)$ & $(0.000)$ \\
\hline Countries & 91 & 93 & 93 & 90 \\
Observations & 316 & 319 & 319 & 302 \\
\hline
\end{tabular}

Note: The column numbering corresponds to that of Table 4. p- values are in parenthesis.

Table 6: Robustness to Measurement Error

\begin{tabular}{|l|cccc|}
\hline & \multicolumn{4}{|c|}{ regression } \\
& $(3)$ & $(4)$ & $(5)$ & $(6)$ \\
\hline potentially & 0.0972 & 0.0635 & 0.0789 & 0.101 \\
biased & $(0.0140)$ & $(0.0141)$ & $(0.0125)$ & $(0.010)$ \\
\hline unbiased & 0.0873 & 0.0925 & 0.105 & 0.145 \\
& $(0.0214)$ & $(0.0246)$ & $(0.020)$ & $(0.026)$ \\
\hline
\end{tabular}

Note: The column numbering corresponds to that of Table 4. Standard errors are in parenthesis. 